\title{
Optical coherence tomography and cognitive dysfunction in Parkinson disease
}

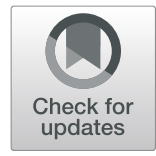

\author{
Takwa H. M. Elkhatib ${ }^{1 *}$ D, Noha A. Hashim¹, Engy M. Emad ${ }^{1}$, Hossam Zein ${ }^{2}$ and Lamiaa El-aidy ${ }^{2}$
}

\begin{abstract}
Background: Parkinson's disease (PD) is a progressive neurodegenerative disease of aging. Optical coherence tomography $(\mathrm{OCT})$ is a simple noninvasive imaging technique to estimate the retinal nerve fiber layer (RNFL) thickness. The aim of this study is to measure the changes of the RNFL thickness in patients with Parkinson disease in comparison with the control group and to detect the relationship between these changes in RNFL with cognitive functions and physical disability in Parkinson patients.

Methods: 20 PD patients (40 eyes) and 20 healthy persons (40 eyes) were enrolled according to the defined criteria. The diagnosis of the patient's Parkinsonism was done according to the brain bank clinical diagnostic criteria for idiopathic Parkinsonism and the severity of the disease was assessed using the Hoehn and Yahr scale. The Montreal Cognitive Assessment (MoCA) was used for cognitive evaluation in all participant subjects. Quality of life was evaluated by Parkinson's disease questionnaire-39 (PDQ-39). Optical coherence tomography (OCT) was done for all patients and control subjects.

Results: The mean RNFL thickness was significantly reduced in Parkinsonian patients with cognitive impairment $(73.64 \pm 1.81 \mu \mathrm{m})$ when compared with those without cognitive impairment $(77.25 \pm 4.53 \mu \mathrm{m})$ and control subjects $(84.1 \pm 6.98 \mu \mathrm{m})(\mathrm{P}<0.001)$. The retinal thickness reduction was statistically significant in superior and inferior quadrants of the retina $(P<0.001, P=0.03$ respectively). The thickness of the superior RNLF correlated significantly with both the Montreal Cognitive Assessment (MoCA) $(r=0.59 ; \mathrm{P}<0.001)$ and the mobility scores according to PDQ 39 scale $(r=-0.39 ; P=0.012)$.
\end{abstract}

Conclusion: Parkinson disease is associated with distinct retinal pathological changes. OCT seems to be a sensitive tool for detecting these retinal changes and correlated significantly with the progression and severity of Parkinson disease.

Keywords: Parkinson, Retina, Retinal nerve fiber layer, Optical coherence tomography, cognitive dysfunction

\section{Introduction}

Parkinson's disease (PD) is ranked as the second common neurodegenerative disorder following Alzheimer disease [1]. Over $1 \%$ of the population above 65 years are affected by this disease, such incidence is expected to be doubled by the year 2030 [2]. Cognitive impairment is one of the non-motor manifestations of Parkinson's disease [3]. Ophthalmic deficits include decreased visual acuity [4], abnormal electro retinographic patterns [5], visual hallucinations, and altered color perception [5]. The underlying etiology of these visual manifestations is not fully understood [6].

\footnotetext{
* Correspondence: takwaaa@ymail.com; takwaaa81@gmail.com ${ }^{1}$ Department of Neurology, Faculty of Medicine, Zagazig University, Sharkia 44519, Egypt

Full list of author information is available at the end of the article
}

Dementias whether cortical or subcortical, both are exhibited in PD; affecting mostly the execution function at an early stage, which appears to deteriorate parallel to the motor degeneration and correlated with the severity of motor system affection [7, 8]. Visual-spatial ability, attention, and memory changes are affected in the later stage of the disease [9].

Histo-pathological changes occurring in the retinal nerve fiber layers (RNFL) can be seen in several neurodegenerative diseases and because the retina has a common embryologic origin of the brain, it considered as the peripheral extension of the brain. This is why the retina is used for the assessment of neurodegenerative disorders [10]. Optical coherence tomography (OCT) is used for assessment of the thickness of RNF [11]. Quantification of 
axonal loss can be estimated by measuring OCT peri-papillary RNFL which allows the indirect estimation of retinal ganglionic cell layer (RGC) impairment [12].

Axonal loss monitoring is essential in parkinsonian patients as it can predict long-term outcomes and disability progression. Consequently, the principal goal of this work is to investigate the association between OCT parameters, cognitive functions, and physical disability in these patients.

\section{Subjects and methods}

\section{Patients and setting}

This was a prospective observational case-control study, conducted in the neurology and ophthalmic departments of Zagazig University Hospitals, Egypt, from February 2017 to May 2018. Twenty patients with Parkinson's disease (PD) (mean age $63.2 \pm 5.50$ years; age range 52-73 years, 10 males and 10 females) were included after 2 years of the appearance of motor symptoms (the median disease duration was $6.53 \pm 3.07$ years).

The diagnosis of the patient's Parkinsonism was done according to the brain bank clinical diagnostic criteria for idiopathic PD [13]. Disease severity rating was assessed according to Hoehn and Yahr [14]. Patients with atypical or other Parkinson syndromes and those with a history of other neurodegenerative diseases such as Alzheimer's disease (AD) and those with multiple sclerosis (MS) were excluded. Also, patients with a history of cognitive impairment in the first year of motor symptoms were excluded. Also, we excluded the presence of any retinal diseases affecting the retinal thickness such as age-related macular degeneration and diabetic retinopathy, individuals with media opacity interfering with the imaging process.

Other study participants consisted of 20 age- and sexmatched ophthalmologically and neurologically healthy subjects (mean age 62.4 \pm 6.96 years; age range 51-73 years, 11 males and 9 females) who were considered as controls. We obtained written informed consent from all patients and controls.

All study participants underwent complete ophthalmologic testing; including assessment of visual acuity and color vision, slit lamp examination, intraocular pressure measurement, visual field assessment, and funduscopy.

Peripapillary RNFL thickness was obtained using the spectral domain OCT device NIDEK RS-3000 Advance (NIDEK, Gamagori, Japan). Pupils were dilated before the examination. Optic disc cube scan protocol was used. Peripapillary RNFL thickness along a circle $3.4 \mathrm{~mm}$ in diameter centered on the optic disc was obtained. Two main output maps were used in the analysis (Fig. 1). The first is the whole thickness map. It gives the average peripapillary RNFL thickness along the whole circumference of the circle. The second is the quadrant map. It divides the peripapillary area into four quadrants and gives the average thickness of each of them. In the two maps, the machine compares the thickness obtained to a normative database and gives green color for probability $>5 \%$, yellow color for probability $<5 \%$ and red color for probability $<1 \%$.

For a rapid evaluation of the cognitive functions, we used the Montreal Cognitive Assessment (MoCA)

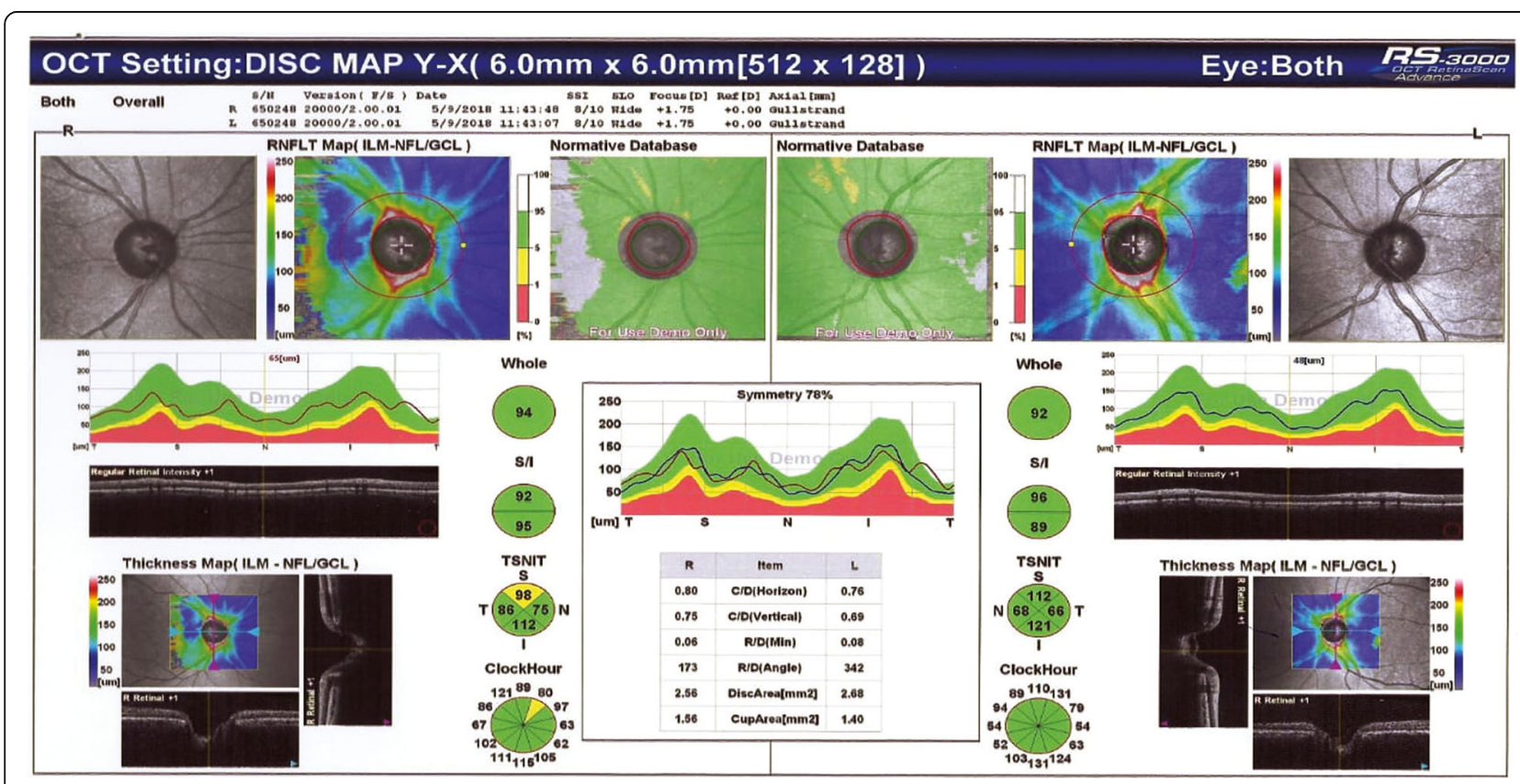

Fig. 1 Outprint of optic disc cube scan by NIDEK RS-3000 Advance machine. The whole thickness map (Whole). The quadrants map (TSNIT). The RNFL thickness is outside the normal limit in the right eye (superior quadrant) 
Arabic version [15] in all study participants. This scale assesses several cognitive domains including attention and concentration, executive functions, short-term memory, language, visuoconstructional abilities, and finally, orientation. It is a 30-point test with a score of 26 or above is considered normal

Quality of life was evaluated by Parkinson's disease quastionnaire-39 (PDQ-39) [16]. A 39-item questionnaire assesses 8 dimensions of quality of life (QoL) including mobility, activities of daily living (ADL), emotional well-being, stigma, social support, cognition, communication, and bodily discomfort. The scores from each dimension are summated into a total score ranging from 0 (best, i.e., never have difficulty) to 100 (worst, i.e., always have difficulty).

\section{Statistical analysis}

All the statistical tests were done using the statistical package of social science (SPSS version, 22) [17]. Qualitative data were presented as number $(\mathrm{N})$ and percentage (\%). Quantitative data were expressed as mean $(\mathrm{M}) \pm$ standard deviation $(\mathrm{SD})$. Chi-square test $(\chi 2)$ test was used to compare between groups. Spearman's correlation analysis was done to patient's parameters with cognitive functions and with retinal nerve fiber layer thickness. All tests were twosided and $P<0.05$ was considered statistically significant.

\section{Results}

\section{Demographics and clinical characteristic}

The study population included 20 patients with Parkinson's disease according to UK Parkinson's disease society brain bank criteria (2006). Ten males and 10 females with mean age $63.2 \pm 5.5$ years and range (52-73 years) and 20 healthy age and gender-matched control group ( 9 females and 11 males) with mean age $(62.4 \pm 6.96$ years $)$ range (51-73 years). There was no significant difference between patients and control groups regarding diabetes mellitus and hypertension (Table 1). Patients had a mean duration of illness $6.53 \pm 3.07$ years and a mean severity scale of $2.9 \pm 0.90$ (Table 1 ).

Cognitive functions assessed by the Montreal scale yield that $70 \%$ of PD patients had cognitive impairment (MoCA $\leq 26)$ with a mean score of $23.5 \pm 3.43$ which was statistically significantly lower than the control group $28.7 \pm 1.27(P<0.001)$ (Table 1$)$. RNFL data were available for both eyes of 20 patients (40 eyes) and 20 control (40 eyes) (Table 2). RNFL thickness was significantly lower in PD patients with cognitive impairment, and this difference was of statistically significant difference in superior $(P<0.001)$ and inferior quadrants $(p=0.003)$ and total thickness $(P<.001)$ (Table 2$)$.

\section{Bivariable correlation}

There was a significant negative correlation between cognitive functions given by MoCA score and age $(P=0.04)$
Table 1 Demographic data of the study subjects

\begin{tabular}{|c|c|c|c|}
\hline & $\begin{array}{l}\text { Patients } \\
(N=20)\end{array}$ & $\begin{array}{l}\text { Control } \\
(N=20)\end{array}$ & $P$ \\
\hline${\text { Age, } \text { years }^{\mathrm{a}}}$ & $\begin{array}{l}63.2 \pm 5.50 \\
(52-73)\end{array}$ & $\begin{array}{l}62.4 \pm 6.96 \\
(51-73)\end{array}$ & 0.69 \\
\hline Male sex ${ }^{b}$ & $10(50 \%)$ & $11(45 \%)$ & 0.8 \\
\hline \multicolumn{4}{|l|}{ Diabetes $^{\mathrm{b}}$} \\
\hline Yes & $7(35 \%)$ & $9(45 \%)$ & 0.5 \\
\hline No & $13(65 \%)$ & $11(55 \%)$ & \\
\hline $\mathrm{HTN}^{\mathrm{b}}$ & & & 0.5 \\
\hline Yes & $9(45 \%)$ & $7(35 \%)$ & \\
\hline No & $11(55 \%)$ & $13(65 \%)$ & \\
\hline Duration of illness, years ${ }^{a}$ & $6.53 \pm 3.07$ & & \\
\hline $\begin{array}{l}\text { Severity of disease by } \\
\text { (Hoehn and Yahr scale) }\end{array}$ & $2.9 \pm 0.90$ & ------- & \\
\hline $1-2.5^{b}$ & $9(45 \%)$ & & \\
\hline $3-5^{b}$ & $11(55 \%)$ & & \\
\hline $\begin{array}{l}\text { Cognitive functions by } \\
\text { (MoCA scale) }^{a}\end{array}$ & $23.5 \pm 3.43$ & $28.7 \pm 1.27$ & $<0.001^{*}$ \\
\hline$>26^{\mathrm{b}}$ & $6(30 \%)$ & $20(100 \%)$ & $<0.001^{*}$ \\
\hline$\leq 26^{\mathrm{b}}$ & $14(70 \%)$ & 0 & \\
\hline
\end{tabular}

HTN hypertension, MoCA Montreal Cognitive Assessment

*significant difference, $p<0.05$

${ }^{a}$ Mean $( \pm S D)$

${ }^{\mathrm{b}}$ Number $(\%)$

and duration of illness $(P=0.04)$ and a highly significant negative correlation with the severity of illness $(P<0.001)$. However, decreased cognitive functions had a significant positive correlation with RNFL thickness in the superior quadrant only. Other quadrants have a positive correlation but with no significant value (Table 3 ).

According to PDQ 39 scale, superior quadrant RNFL thickness has a significant negative correlation with mobility $(P=0.012)$, ADL $(P=0.012)$, stigma $(P=0.02)$, social support $(P=0.04)$, cognition $(P<0.003)$, communication $(P<0.001)$, and bodily discomfort $(P=0.03)$. Also, inferior quadrant RNFL thickness has a significant negative correlation with mobility $(P=0.03)$; otherwise, there was no significant correlation between RNFL thickness and PDQ 39 scale (Table 4).

When we correlated OCT findings to other clinical data of patients, they revealed that the superior quadrant RNFL thickness had a significant negative correlation with the duration of illness $(P=0.002)$ and age $(P=0.004)$ and the severity of illness $(P=0.001)$. Also, inferior quadrant RNFL thickness has a significant negative correlation with the duration of illness $(P=0.02)$. Also, total thickness had a significant negative correlation with age $(P=0.02)$ and severity of disease $(P=0.03)$ (Table 4$)$.

\section{Discussion}

Developing biomarkers for Parkinson disease to predict the clinical progression and the expected disability may 
Table 2 RNFL thickness in the study populations

\begin{tabular}{|c|c|c|c|c|c|}
\hline & Temporal & Nasal & Inferior & Superior & Mean \\
\hline \multicolumn{6}{|l|}{ Patients } \\
\hline With normal cognitive ${ }^{a}$ & $56.42 \pm 3.73$ & $64.6 \pm 3.35$ & $107.7 \pm 5.52$ & $96.7 \pm 5.97$ & $77.25 \pm 4.53$ \\
\hline With cognitive impairment ${ }^{a}$ & $56.20 \pm 2.19$ & $61.11 \pm 2.27$ & $95.5 \pm 3.35$ & $83.39 \pm 4.27$ & $73.64 \pm 1.81$ \\
\hline Controls $^{a}$ & $57.65 \pm 8.50$ & $63.08 \pm 10.57$ & $111.2 \pm 15.81$ & $108.74 \pm 14.40$ & $84.1 \pm 6.98$ \\
\hline$P$ & 0.62 & 0.38 & $<0.001$ & $<0.001^{* *}$ & $<0.001^{* *}$ \\
\hline$p^{\otimes}$ & $0.02^{*}$ & 0.72 & $0.003^{*}$ & $<0.0001^{* *}$ & $<0.0001^{* *}$ \\
\hline
\end{tabular}

${ }^{\mathrm{a}}$ Mean $( \pm \mathrm{SD}) ;$ RNFL retinal nerve fiber layer

NB. $P^{\oplus}$ all patients vs control

* significant difference

** highly significant difference

improve the management of those patients and can be helpful for evaluating the effectiveness of the therapy [18]. RNFL thickness can be considered as a promising tool detecting the progression of many neurodegenerative diseases [18].

In this study, we evaluated the relationship between the changes in RNFL thickness, cognitive dysfunction, and physical disability in Parkinson patients. Our data indicated that cognitive impairment using the Montreal scale was more common in Parkinson patients $(P<0.001)$ in context with Aarsland et al. [19] and Litvan et al. [20] who reported that cognitive impairment is apparent in many cases from early stages. The risk of dementia in Parkinson's disease patients is six times higher than in the healthy population [21].

Cooper et al. [22] suggested that the pathological mechanisms of cognitive impairment of Parkinson disease could be related to the extrastriatal dopaminergic system dysfunction or non-dopaminergic system disturbances. Cerebral mitochondrial abnormalities of PD are associated with synaptic protein dysmetabolism that could trigger cell damage and cortical atrophy, leading to cognitive dysfunction.

Compared to the control group, we found more attenuation of RNFL thickness in all quadrants in PD patients.

Table 3 Bivariable correlation between cognitive functions and disease parameters in the patients' group

\begin{tabular}{|c|c|c|c|}
\hline & \multicolumn{2}{|c|}{ Montreal cognitive scale } \\
\hline & & $r$ value & $P$ value \\
\hline \multicolumn{2}{|l|}{ Age } & -0.46 & $0.04^{*}$ \\
\hline \multicolumn{2}{|c|}{ Duration of illness } & -0.45 & $0.04^{*}$ \\
\hline \multicolumn{2}{|c|}{ Severity of disease } & -0.82 & $<0.001^{* *}$ \\
\hline \multirow[t]{5}{*}{ OCT } & Superior & 0.59 & $<0.001^{* *}$ \\
\hline & Inferior & 0.054 & 0.74 \\
\hline & Nasal & 0.09 & 0.6 \\
\hline & Temporal & 0.18 & 0.26 \\
\hline & Mean & 0.29 & 0.064 \\
\hline
\end{tabular}

OCT optical coherence tomography

* significant difference

** highly significant difference
This attenuation was of significant difference at the superior $(P<0.0001)$, inferior quadrant $(P=0.003)$, temporal $(P<0.05)$, and total thickness $(P<0.0001)$. Our results are strengthened by previous studies that reported marked thinning of RNFL thickness in patients with Parkinson disease. Tsironi et al. [21] in their meta-analysis showed a statistically significant reduction in RNFL thickness in all quadrants of PD patients. Also, Moschos et al. [23] found a significant thinning in the inferior and temporal quadrant of the RNFL thickness. Other reports revealed that there was a clear reduction of RNFL thickness in superior and inferior quadrants in PD [24]. Yu et al. [18] in their meta-analysis found a significant thinning of RNFL in the temporal quadrant.

To clarify the retinal pathological changes of RNFL thinning in PD, Garcia-Martin et al. [25] reported that PD is characterized by the death of pigmented dopaminergic neurons of the substantia nigra with concomitant retinal dopaminergic neuronal loss. These dopaminergic retinal cells are located in the inner nuclear layer of the retina, communicating with other amacrine cells, modulating the connection between bipolar and retinal ganglion cells and providing input to the retinal ganglion cells. The retinal ganglion cells degeneration would mediate the reduction of RNFL thickness, which can be detected by OCT in patients with PD [26]. OCT technology could detect accurate measurement of retinal layer thickness that indicates the number of retinal cells and its dopaminergic activities [27]. In addition, Djamgoz et al. [28] in their study added that RNFL thinning could be considered a strong indicator of axonal damage in PD.

Another explanation for RNFL thinning in Parkinson disease by Jindahra et al. [29], who demonstrated that posterior visual pathway pathological changes occurred during the course of the disease and could be evaluated by OCT. These changes include retrogeniculate ganglion degeneration with retrograde transsynaptic degeneration of retinal ganglion cells and their axons resulting in RNFL thinning [29]. Recently, it was proved there is $\alpha-$ synuclein deposits in the retina of PD patients with a significant reduction of foveal and macular thickness and marked RNFL thinning [30]. 
Table 4 Correlation between RNFL thickness and study parameters in the patients group

\begin{tabular}{|c|c|c|c|c|c|c|c|c|c|c|c|}
\hline \multirow{2}{*}{$\begin{array}{l}\text { RNFL } \\
\text { thickness }\end{array}$} & \multicolumn{8}{|c|}{ PDQ-39 Questionnaire } & \multirow{2}{*}{$\begin{array}{l}\text { Duration } \\
\text { of illness }\end{array}$} & \multirow[t]{2}{*}{ Age } & \multirow{2}{*}{$\begin{array}{l}\text { Severity } \\
\text { of diseas }\end{array}$} \\
\hline & Mobility & $\mathrm{ADL}$ & $\begin{array}{l}\text { Emotional } \\
\text { well being }\end{array}$ & Stigma & $\begin{array}{l}\text { Social } \\
\text { support }\end{array}$ & Cognitions & Communication & $\begin{array}{l}\text { Bodily } \\
\text { discomfort }\end{array}$ & & & \\
\hline Superior & -0.39 & -0.39 & -0.21 & -0.4 & -0.32 & -0.54 & -0.51 & -0.35 & -0.47 & -0.44 & -0.5 \\
\hline$P$ value & $0.012^{*}$ & $0.012^{*}$ & 0.2 & $0.02^{*}$ & $0.04^{*}$ & $<0.001^{* *}$ & $<0.001^{* *}$ & $0.03^{*}$ & $0.002^{* *}$ & $0.004^{* *}$ & $0.001^{* *}$ \\
\hline Inferior & -0.35 & -0.24 & -0.094 & 0.13 & -0.07 & 0.02 & -0.12 & 0.14 & -0.36 & -0.29 & -0.22 \\
\hline$P$ value & $0.03^{*}$ & 0.13 & 0.56 & 0.43 & 0.6 & 0.91 & 0.52 & 0.40 & $0.02^{*}$ & 0.06 & 0.17 \\
\hline Nasal & -0.044 & -0.06 & 0.05 & -0.20 & -0.08 & -0.15 & -0.04 & -0.19 & 0.034 & -0.30 & -0.19 \\
\hline$P$ value & 0.8 & 0.74 & 0.8 & 0.21 & 0.62 & 0.37 & 0.8 & 0.24 & 0.83 & 0.06 & 0.22 \\
\hline Temporal & -0.014 & -0.12 & 0.16 & -0.27 & 0.08 & -0.15 & -0.14 & -0.095 & -0.19 & -0.23 & -0.20 \\
\hline$P$ value & 0.93 & 0.45 & 0.32 & 0.09 & 0.63 & 0.36 & 0.38 & 0.6 & 0.24 & 0.17 & 0.21 \\
\hline Total thickness & -0.12 & -0.23 & 0.05 & -0.24 & -0.07 & -0.28 & -0.24 & -0.06 & -0.28 & -0.38 & -0.33 \\
\hline$P$ value & 0.46 & 0.15 & 0.78 & 0.14 & 0.67 & 0.08 & 0.13 & 0.71 & 0.08 & $0.02^{*}$ & $0.03^{*}$ \\
\hline
\end{tabular}

PDQ-39 Parkinson's disease questionnaire-39, $A D L$ activities of daily living

* significant difference

** highly significant difference

To evaluate the relation between the degree of RNFL thinning and cognitive dysfunction, we found more reduction of RNFL thickness in PD patients with cognitive impairment in comparison with those without cognitive impairment. This reduction was of significant value in the superior, inferior quadrant, and total thickness. In addition, our results revealed that RNFL thinning in superior quadrant correlated significantly with cognitive decline in PD patients. This is in context with Shen et al. [31] who reported that marked thinning of superior RNFL was highly associated with cognitive deterioration. Liu et al [32] reported great thinning of the superior and inferior quadrant in Alzheimer's disease compared to normal. Furthermore, Khawaja et al [33] found RNFL thickness was significantly correlated with several cognitive domains.

Evolving data supported the presence of many cerebral pathologies of dementia which occur in the retina of $\mathrm{PD}$ patients [34]. Histopathological studies showed the accumulation of beta-amyloid $(\mathrm{A} \beta)$ plaques with the presence of hyperphosphorylated tau in the inner retinal layers [35] which are closely similar to cerebral amyloid plaque existed in AD [36]. Therefore, the amyloid deposition in the retina results in retinal ganglion cell degeneration, which could be associated with the related amyloid neurodegeneration in the brain [37]. Moreover, La Morgia et al. [38] proved that there is a subgroup of the retinal ganglion cells that contain melanopsin photoreceptors [melanopsin-containing retinal ganglion cells (mRGCs)] controlling the circadian photoentrainment to the light/ dark cycles. They stated that RGC degenerations by amyloid plaques causing circadian dysfunction in PD patients which were associated with OCT changes.

Kirby et al. [39] reported that damage of retinal parvo and magnocellular cells was attributed to retinal amyloid deposits which lead to visual problems and visuospatial dysfunction in dementia. Another finding in AD, the related retinal angiopathic changes include narrowed veins, increased tortuosity, and reduction of blood flow which are similar to cerebral vascular related changes [40].

Anatomically, Liu et al. [32] provide a possible explanation for selective RNFL thinning in superior quadrant reporting that axons from superior retina project to the cuneal gyrus of the primary visual cortex; however, those from inferior retina project to the lingual gyrus. Armstrong [41] in his histopathological study of AD discover more accumulation of $\mathrm{A} \beta$ plaques and neurofibrillary tangles in the cuneal gyrus than in the lingual gyrus, suggesting that differences might explain marked thinning of superior retinal fibers. While Carelli et al. [42] reported that inferior and temporal retinal sectors are highly susceptible in neurodegenerative disorders.

In the present study, cognitive dysfunction in PD patients was significantly correlated with age, duration, and the severity of the disease. Approximately, $80 \%$ of PD patients developed dementia after 15-20 years [43]. Different studies pointed at the strong association between the severities of motor symptoms and cognitive dysfunction [44]. PD patients with axial symptoms, gait disturbances, and motor symptoms, that are refractory to the dopaminergic treatment, have a high tendency to develop severe cognitive decline [45].

Our results clearly revealed significant negative correlations between superior and total RNFL thickness with the duration and severity of the Parkinson disease. The results of Moschos et al. [23] and Tsironi et al. [21] are in line with our findings. Also, Garcia-Martin et al. 2014 [27] reported that the retinal fibers thinning could be the predictor of significant axonal damage in PD and added that the negative correlation between the thickness of RNFL and patient's scores of Hoehn and Yahr 
scale is indicating that PD patients with axonal damage have a great tendency to develop aggressive PD.

This study showed that in PD patients, there was a significant association between superior RNFL thinning and the deterioration in the quality of life using PDQ39 scale (mobility, ADL, stigma, social support, cognition, and bodily discomfort). Following our results, Garcia-Martin et al. 2014 [27] reported that marked impairment of RNFL thickness was associated strongly with lower quality of life and severe Parkinson disease. In PD, loss of dopamine has dangerous effects on physical mobility and reward-seeking behavior. It is suggested that reduced dopaminergic input to retinal ganglion cells, resulting in excess glutamate and glycine production that possibly cause marked atrophy of the retinal nerve fibers [24].

\section{Conclusion}

Parkinson disease is associated with distinct retinal pathological changes. OCT seems to be a sensitive tool for detecting these retinal changes and therefore detecting the progression and severity of Parkinson disease.

\section{Abbreviations}

AD: Alzheimer's disease; ADL: Activities of daily living; $A \beta$ : Beta-amyloid; MoCA: Montreal Cognitive Assessment; mRGC: Melanopsin-containing retinal ganglion cells; MS: Multiple sclerosis; OCT: Optical coherence tomography; PD: Parkinson's disease; PDQ-39: Parkinson's disease questionnaire-39; RGC: Retinal ganglion cell; RNFL: Retinal nerve fiber layer

\section{Acknowledgements}

Not applicable.

\section{Authors' contributions}

THME, NAH, EME, HZ, and LE carried out the work. THME, NAH, and EME contributed to the selection of the subject and developed the research plan, collected the patients, carried out the clinical examination of the patients and their diagnosis, gathered the clinical data, wrote the manuscript, designed the study, and had done the statistical analysis. HZ and LE had done the investigational work of the study and improvised the manuscript for intellectual content. All authors were involved in drafting the article or revising it critically for important intellectual content, and all authors read and approved the final version to be published.

\section{Funding}

There is no source of funding for the research.

\section{Availability of data and materials}

Data and materials supporting the results of this article are included within the article (and its additional file(s)).

\section{Ethics approval and consent to participate}

The study was approved from the Institutional Ethics Committee of the Faculty of Medicine, Zagazig University (ZU-IRB \#4902/17-10-2018). Written informed consent was obtained from all study participants after explaining the details and benefits as well as risks to them. Surrogate consent from the patient's legal guardian or designated health proxy was permitted in cases where the patient did not have decision-making capacity.

\section{Consent for publication}

Consent has been obtained from the participants involved in the study to report their individual patient data.

\section{Competing interests}

The authors declare that they have no competing interests.

\section{Author details}

'Department of Neurology, Faculty of Medicine, Zagazig University, Sharkia 44519, Egypt. ${ }^{2}$ Department of Ophthalmology, Faculty of Medicine, Zagazig University, Sharkia, Egypt.

Received: 27 September 2018 Accepted: 7 July 2019

Published online: 29 July 2019

\section{References}

1. Braak H, Del Tredici K, Bratzke H, Hamm-Clement J, Sandmann-Keil D, Rüb $U$. Staging of the intracerebral inclusion body pathology associated with idiopathic Parkinson's disease (preclinical and clinical stages). J Neurol. 2002; 249(Suppl 3):III-1-5.

2. Dorsey ER, Constantinescu R, Thompson JP, and colleagues. Projected number of people with Parkinson disease in the most populous nations, 2005 through 2030. Neurology 2007; 68:384-386.

3. Shulman LM, Taback RL, Bean J, Weiner WJ. Comorbidity of the nonmotor symptoms of Parkinson's disease. MovDisord. 2001;16:507-10.

4. Rodnitzky RL. Visual dysfunction in Parkinson's disease. Clin Neurosci. 1998;5: 102-6.

5. Tagliati M, Bodis-Wollner I, Yahr MD. The pattern electroretinogram in Parkinson's disease reveals lack of retinal spatial tuning. Electroencephalogr Clin Neurophysiol. 1996;100:1-11.

6. Pieri V, Diederich NJ, Raman R, Goetz CG. Decreased color discrimination and contrast sensitivity in Parkinson's disease. J Neurol Sci. 2000;172:7-11.

7. Mollenhauer B, Förstl H, Deusehil G, et al. Lewy body and parkinsonian dementia: common, but often misdiagnosed conditions. DtschArztebl Int. 2010;107(39):684-91

8. Nazem S, Siderowf AD, Duda JE, et al. Montreal cognitive assessment performance in patients with Parkinson's disease with "normal" global cognition according to mini-mental state examination score. J Am Geriatr Soc. 2009;57(2):304-8.

9. Owen AM. Cognitive dysfunction in Parkinson's disease: The role of fronto striatal circuitry. Neuroscientist. 2004;10(6):525-36.

10. Altintas $\mathrm{O}$, Iseri P, Ozkan B, et al. Correlation between retinal morphological and functional findings and clinical severity in Parkinson's disease. Doc Ophthalmol. 2008;116:137-46.

11. Jaffe GJ, Caprioli J. Optical coherence tomography to detect and manage retinal disease and glaucoma. Am J Ophthalmol. 2004;137(1):156-69.

12. Monteiro ML, Fernandes DB, Apostolos-Pereira SL, et al. Quantification of retinal neural loss in patients with neuromyelitisoptica and multiple sclerosis with or without optic neuritis using Fourier-domain optical coherence tomography. Invest Ophthalmol Vis Sci. 2012;53:3959-66.

13. Hughes AJ, Daniel SE, Kilford L, et al. Accuracy of clinical diagnosis of idiopathic Parkinson's disease. A clinico-pathological study of 100 cases. JNNP. 1992;55:181-4.

14. Goetz CG, Poewe W, Rascol O. Movement disorder society task force report on the Hoehn and Yahr staging scale: status and recommendations. Mov Disord. 2004;19:1020-8.

15. Nasreddine ZS, Phillips NA, Bédirian V, Charbonneau S, Whitehead V, Collin I, Cummings JL, Chertkow H. The Montreal Cognitive Assessment (MoCA): a brief screening tool for mild cognitive impairment. J Am Geri Soci. 2005;53(4):695-9.

16. Peto V, Jenkinson C, Fitzpatrick R, et al. The development and validation of a short measure of functioning and well being for individuals with Parkinson's disease. Qual Life Res. 1995;4:241-8.

17. Levesque R. SPSS programming and data management: a guide for SPSS and SAS users. 4th ed. Chicago: SPSS Inc; 2007. ISBN 1-56827-390-8

18. Yu JG, Feng YF, Xiang Y, Huang JH, Savini G, Parisi V, Yang WJ, Fu XA. Retinal nerve fiber layer thickness changes in Parkinson disease: A metaanalysis. PLoS One. 2014;9(1):e85718.

19. Aarsland D, Andersen K, Larsen JP, Perry R, Wentzel-Larsen T, Lolk A, KraghSørensen P. The rate of cognitive decline in Parkinson disease. Arch Neurol. 2004:61:1906-11.

20. Litvan I, Aarsland D, Adler CH, Goldman JG, Kulisevsky J, Mollenhauer B, Rodriguez-Oroz MC, Tröster Al, Weintraub D. MDS Task Force on mild cognitive impairment in Parkinson's disease: critical review of PD-MCI. Mov Disord. 2011;15:1814-24.

21. Tsironi EE, Dastiridou A, Katsanos A, Dardiotis E, Veliki S, Patramani G, Hadjigeorgiou GM. Perimetric and retinal nerve fiber layer findings in patients with Parkinson's disease. BMC Ophthalmol. 2012;12:54. 
22. Cooper JA, Sagar HJ, Jordan N, Harvey NS, Sullivan EV. Cognitive impairment in early, untreated Parkinson's disease and its relationship to motor disability. Brain. 1991;114(5):2095-122.

23. Moschos MM, Tagaris G, Markopoulos I, Margetis I, Tsapakis S, Kanakis M, et al. Morphologic changes and functional retinal impairment in patients with Parkinson disease without visual loss. Eur J Ophthalmol. 2011;21:24-9.

24. Inzelberg R, Ramirez JA, Nisipeanu P, Ophir A. Retinal nerve fiber layer thinning in Parkinson disease. Vision Res. 2004;44:2793-7.

25. Garicia-Martin E, Satue M, Otin S, Fuertes I, Alarcia R, Larrosa J, Polo V, Pablo L. Retina measurement for diagnosis of Parkinson disease. Retina J. 2014;34:971-80

26. Archibald N, Clark M, Mosimann U, Burn D. The retina in Parkinson's disease. Brain. 2009;132(5):1128-45.

27. Garicia-Martin E, Larrosa J, Polo V, Satue M, Marques M, Seral M, Fuertes I, Otin S, Pablo L. Distribution of retinal layer atrophy in patients with Parkinson disease and association with disease severity and duration. Am J Ophthalmol. 2014;157:470-8.

28. Djamgoz MBA, Hankins MW, Hirano J, Archer SN. Neurobiology of retinal dopamine in relation to degenerative states of the tissue. Vision Res. 1997; 37(24):3509-29.

29. Jindahra P, Petrie A, Plant G. Retrograde trans-synaptic retinal ganglion cell loss identified by optic coherence tomography. Brain. 2009;132(pt 3):628-34.

30. Bodies-Wollner I, Kozlowski P, Glazman S, Miri S. Alpha-Synuclein in the inner retina in Parkinson disease. Ann Neurol. 2014;75:964-6.

31. Shen $Y$, Shi Z, Jia $R$, et al. The attenuation of retinal nerve fiber layer thickness and cognitive deterioration. Front Cell Neurosci. 2013;7:142.

32. Liu D, Zhang L, Li Z, Zhang $X$, Wu Y, Yang $H$, et al. Thinner changes of the retinal nerve fiber layer in patients with mild cognitive impairment and Alzheimer's disease. BMC Neurol. 2015;15:14.

33. Khawaja AP, Chan MP, Yip JL, Broadway DC, Garway-Heath DF, Luben R, Foster PJ. Retinal Nerve Fiber Layer Measures and Cognitive Function in the EPIC-Norfolk Cohort Study. Invest Ophthalmol Vis Sci. 2016;57(4):1921-6.

34. Doustar J, Torbati T, Black KL, Koronyo Y, Koronyo-Hamaoui M. Optical Coherence Tomography in Alzheimer's disease and Other Neurodegenerative Diseases. Front Neurol. 2017;8:701-13.

35. Valenti DA. Alzheimer's disease and glaucoma: imaging the biomarkers of neurodegenerative disease. Int J Alzheimers Dis. 2011;2010:793931.

36. Koronyo Y, Biggs D, Barron E, Boyer DS, Pearlman JA, Au WJ, et al. Retinal amyloid pathology and proof-of-concept imaging trial in Alzheimer's disease. JCl Insight. 2017;2(16):e93621.

37. Guo L, Duggan J, Cordeiro MF. Alzheimer's disease and retinal neurodegeneration. Curr Alzheimer Res. 2010;7(1):3-14.

38. La Morgia C, Ross-Cisneros FN, Sadun AA, Carelli V. Retinal ganglioncells and circadian rhythms in Alzheimer's disease, Parkinson's disease, and beyond. Front Neurol. 2017:8:162.

39. Kirby E, Bandelow S, Hogervorst E. Visual impairment in Alzheimer's disease: a critical review. J Alzeimers Dis. 2010;21(1):15-34.

40. Einarsdottir AB, Hardarson SH, Kristjansdottir JV, Bragason DT, Snaedal J, Stefansson E. Retinal oximetry imaging in Alzheimer's disease. J Alzheimers Dis. 2015;49:79-83.

41. Armstrong RA. Visual field defects in Alzheimer's disease patients mayreflect differential pathology in the primary visual cortex. Optom Vis Sci. 1996; 73(11):677-82

42. Carelli V, La Morgia C, Valentino M, Barboni P, Ross-Cisneros F. Retinal ganglion cell neurodegeneration in mitochondrial inherited disorders Biochim Biophys Acta. 2009;1787:518-28.

43. Aarsland D, Kurz MW. The epidemiology of dementia associated with Parkinson's disease. Brain Pathol. 2010;20:633-9.

44. Katzen $\mathrm{HL}$, Levin BE, Weiner W. Side and type of motor symptom influence cognition in Parkinson's disease. Mov Disord. 2006:21:1947-53.

45. Verbaan D, Marinus J, Visser M, van Rooden SM, Stiggelbout AM, Middlekoop HA, Van Hilten JJ. Cognitive impairment in Parkinson's disease. J Neurol Neurosurg Psychiatry. 2007;78:1182-7.

\section{Publisher's Note}

Springer Nature remains neutral with regard to jurisdictional claims in published maps and institutional affiliations.

\section{Submit your manuscript to a SpringerOpen ${ }^{\circ}$ journal and benefit from:}

- Convenient online submission

- Rigorous peer review

- Open access: articles freely available online

- High visibility within the field

- Retaining the copyright to your article

Submit your next manuscript at $\boldsymbol{\nabla}$ springeropen.com 